Tolga AKKUŞ / Dijital Minimalizm: Ekran Bağımlılı̆̆ı ve Teknoloji Yorgunluğu Sarmalından Kurtulmak İçin Bir Yol Haritası

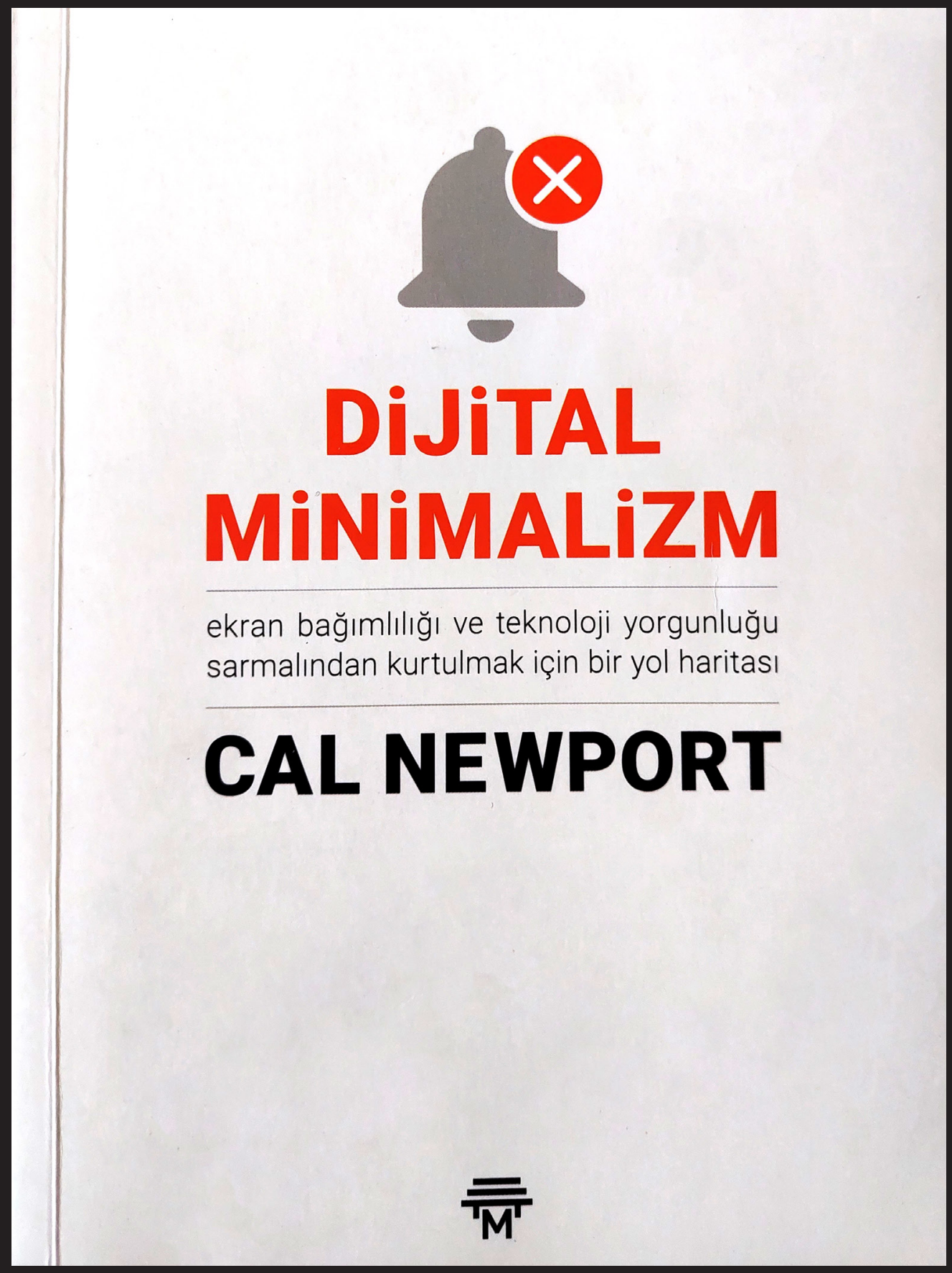




\title{
TRTaKadeмi
}

ISSN 2149-9446 | Cilt 07 | Sayı 14 | Ocak 2022 | Sosyal Medya

\section{Dijital Minimalizm: Ekran Bağımlılığı ve Teknoloji Yorgunluğu Sarmalından Kurtulmak İçin Bir Yol Haritası}

\author{
Dijital Minimalizm: Ekran Bağımlılığı ve Teknoloji Yorgunluğu Sarmalından Kurtulmak İçin Bir Yol Haritası \\ Cal Newport (2019), Türkçeye Çeviren: Cansen Mavituna \\ 1.Baskı, İstanbul, Metropolis Yayıncılık, 240 Sayfa \\ ISBN 978-605-66693-7-8
}

\section{Tolga AKKUŞ*}

Dijital Minimalizm kitabı Georgetown Üniversitesi'nde bilgisayar bilimi doçenti olarak görev yapan Cal Newport tarafindan kaleme alınmıştır. Kitabın yazarı eserini "Ekran bağımlılığı ve teknoloji yorgunluğu sarmalından kurtulmak için bir yol haritası" olarak tanımlamaktadır.

Çalışmaktan çok odaklanmanın önem kazandığı günümüzde bir bilgi bombardımanı altıdayız. Bu sebeple Dijital Minimalizm kitabı verdiği öneriler ve sunduğu çözüm yöntemleri ile başta anne babalar ve öğrenciler olmak üzere toplumun her kesimine önemli dersler vermektedir. Dijital medya şirketlerinin ağına düşen fakat bunun farkında olmayan ya da nasıl kurtulacağını bilmeyen kişilere önemli tavsiyeler veren Cal Newport, her boşluğa düştüğünde eli telefona giden dijital abur cubur bağımlılarının kendilerini sorgulamalarını sağlamaktadır. Kitabın en önemli özelliklerinden bir tanesi de okuyucularını, sosyal medya bağımlısı olup olmadıkları konusunda kendilerini sorgulamaya yöneltmesidir, yazar sorduğu sorular ile her kullanıcının aslında ne kadar büyük bir tehlikede olduğuna da dikkati çekmektedir.

Cal Newport sosyal medya mecralarının bir döviz bürosu gibi çalıştı̆̆ına vurgu yaparak bu mecraların aslında bedelsiz olarak çalışmadığını okurlara aktarmaktadır. Yazar, dikkatin değerli ve kıt bir kaynak olduğunu, dikkat çekmenin de pahalı bir uğraş olduğu okurlara sıklıkla hatırlatmaktadır. Kitapta dünyanın en değerli şirketlerinden birisi olan ve adını Meta olarak değiştiren Facebook'un ilk kurulduğunda bildirim butonunun mavi olduğu fakat yeterince ilgi çekmediği, bu butonun renginin dikkat çekici bir renk olan kırmızı ile değiştiğinde ise tıklanma rekorları kırdığı anlatılmaktadır. 
Dijital teknolojilerin henüz bu kadar gelişmediği ve internetin hava ya da su gibi bir "ihtiyaç" haline gelmediği günlerde yapılan sohbetlerden dem vuran Newport, dijital bağımlılıkların ve FOMO yani gözden kaçırma korkusunun hayattan tat almayı engellediğini fakat kimsenin bundan haberdar olmadığını da ifade etmektedir. Neredeyse her işin internetten yapılabilmesini ve dijital dönüşümün hayatı kolaylaştırmasını önemli bir gelişme olarak gören fakat teknolojinin bilinçsiz kullanımının insanları hapsettiğini düşünen yazar Pürdikkat isimli eserinden sonra Dijital Minimalizm kitabında da dikkat ve odaklanma konusunda önemli tavsiyeler sunmaktadır. "Internet olmadan yaşayamam” diyen kişilere internetsiz nasıl yaşanacağını da anlatan ve dijital bağımlılıkları yüzünden hayatı yaşanmaz hale gelen kullanıcılara gerekli yol haritasını ve yolları sunan Newport, teknolojinin sunduğu albeniye rağmen teknolojiden faydalanarak, teknoloji olmadan da yaşanabilecek hayatlar kurmayı öğretmektedir.

Eserde insanların sıkılmaktan korktukları fakat bunu kimseyle hatta kendileri ile bile paylaşmadıkları ifade edilmektedir. Cal Newport'a göre insanlar yalnız kalamamaktadır ve "yalnızlık yoksunluğu" çekmektedir. İnsanlar önce sıkılmaktan korktukları için yalnız kalmasa da sonrasında isteseler de yalnız kalamamaktadır. Insanların yalnız kalmak için özel bir çaba göstermeleri gerekmektedir, yazar bu durumu "gönüllü yalnızlık" olarak kavramsallaştırmıştır.

Sosyal medya mecralarındaki bildirimleri ve akışı takip eden kişiler birer bağımlı gibi her an yeni bir hareket olduğunu kontrol etmektedir. Newport da bu durumu sigara şirketleri ile karşılaştırmaktadır ve kullanıcıların gönderilerindeki beğeni sayılarını istemsizce kontrol etmelerini sigara tiryakiliğine benzetmektedir. Yazar sigara şirketlerinin insanların ciğerlerinin peşinde olduğunu, sosyal medya şirketlerinin de insanların ruhlarının peşinde olduğunu ifade etmektedir. Eserinde FOMO yani gözden kaçırma korkusuna da değinen yazar zaman tüneli akışının insanları bir akarsu gibi kapabileceğini ifade etmektedir. Bu durum Herakleitos'un "Aynı nehirde iki kere yıkanılmaz" sözünü hatırlatmaktadır, bugün de aynı zaman tüneline iki kere girmek imkansızdır, zaman tünelinde her an yeni akışlar vardır ve bunu kaçırmamak isteyen kullanıcılar bir süre sonra akış bağımlısı olmaktadır.

Dijital Minimalizm kitabında öne çıkarılan "dikkat ekonomisi” kavramı, insanların dikkatini çekmek için kurulan endüstri ile ilgili önemli bilgiler vermektedir. Kitapta Tim Wu tarafindan yazılan "Dikkat Tacirleri” isimli eserden de bahsedilerek insanların dikkatini çekmenin önemli bir sektör oluşturduğundan ve sosyal medya mecralarının da bu sektöre hizmet ettiğinden bahsedilmektedir. Dikkatin internet ile her an kullanıcılarını kendine çekmesini yazar "Her daim bağlantıda olmamızı talep eden bir çağ" olarak yorumlamaktadır. Kitapta, sosyal medya mecralarının 
kullanıcıların verilerini toplayarak onlar hakkında bilgi sahibi olduğu ve buna uygun reklamlar gösterildiği anlatılmaktadır. Kişilerin hangi an neyi görmek istediklerini tahmin eden ve bir "dikkat avcısı" olarak çalışan dijital mecralar kullanıcıları bir yankı odasına hapsetmektedir.

Yazarın "Pürdikkat" isimli eserinde de bahsettiği "dijital obezite" kavramı, kullanıcıların alabileceklerinden ve algılayabileceklerinden daha fazla bilgi almaları ile ruhsal sorunlar yaşayabileceklerini açıklamaktadır. Yazar, sosyal medyadaki gereksiz bilgilerin aynı vücutta biriken yağ tabakası gibi zihni sardığını ve bu mecralardaki dijital abur cuburların bir sosyal fast-food gibi "sağlıksız zihni besinler" olduğunu düşünmektedir. Sosyal medya mecralarının insan ilişkilerini de olumsuz yönde etkilediğini ifade eden Newport "sosyalleşme illüzyonu" kavramını öne sürmekte ve dijital mecraların ilişkileri önemsiz hale getirdiğini, insanların birbirlerine yeterince önem verdiğini düşünmelerinin bir yanılgı olduğunu ifade etmektedir. Kırmızı ışıkta durduğunda, bir sohbet 5 saniyeliğine kesintiye uğradığında ya da her sıkıldığı anda telefona sarılan insanlar Newport'a göre birer dijital obez adayıdır.

Sosyal medya mecralarını kullanan her kullanıcının pazarlanan bir ürüne dönüştüğünü düşünen yazar, kendisini satışa çıkmış bir ürün olarak gören kullanıcılara seslenmektedir. İnternete değil gerçek hayata bağlı bir yaşam sürmek isteyen herkese hitap eden bu kitap teknolojik gelişmelere boyun eğen, gözden kaçırma korkusu ile zaman tünellerinde mahsur kalan teknoloji mağdurlarına önemli tavsiyeler vermektedir. Yazar dijital minimalizm felsefesini anlatirken teknolojinin fayda sağlayan unsurlarının hayata entegre edilmesini fakat gereksiz ve zaman kaybına neden olan dijital abur cuburların zihinden dünyadan uzak tutulmasını tavsiye etmektedir.

Cal Newport'a göre "Bu kadar çok insanla irtibat halinde olmamıza gerek yok" bu sebeple kitapta dunbar sayısından bahsediyor, yazar insanların belirli bir sayıda insandan sonrasına ihtiyacının olmadığını düşünmektedir. Okurlarını dikkat direnişine davet eden yazar, kullanıcıları dikkatlerine sahip çıkmaya davet etmektedir. Dijital minimalizm düşüncesi, teknoloji kullanıcılarını teknolojiden uzak durmaya değil teknolojik gelişmeleri hayata doğru şekilde entegre etmeye ve gerçek hayattan kopmamaya davet etmektedir. Dijital dönüşümün hızlandığı günümüzde bu dönüşümün aynı zamanda insan zihninde de olduğu ve buna göre davranılması gerektiği tavsiyesi verilmektedir. Newport, teknolojiden uzaklaşmak yerine ona temkinli yaklaşmayı ve teknoloji deneyimini bilinçli şekilde sürdürmeyi öğütlemektedir. 
Dijital bağımlılık tuzağına düşen okurlarına, zamanlarını teknoloji şirketlerine para kazandırmak yerine kendilerine ayırmaları gerektiğini tavsiye eden yazar "vakit sizin kazanç onların" sözüyle bu durumu vurucu şekilde ifade etmektedir. Kullanıcıların internete bağlı cihazları kullanırken nasıl etki altında kalmayacağı ve bu zamanın nasıl azaltılacağının yollarının anlatıldığı kitapta boş zamanların sosyal medya mecralarına değil kaliteli aktivitelere ayrılmasının önemi vurgulanmaktadır. Teknoloji şirketlerinin tehlikeli yönlerinin anlatıldığı kitapta dijital minimalizm felsefesi sadece düşünsel olarak değil uygulamalı şekilde de anlatılmaktadır. Okurlarına 30 günlük bir dijital minimalizm programı öneren yazar bu durumu bir "dijital detoks" olarak yorumlayanların başarısız olacağını ve bunun bir irade savaşı olduğunu açıklamaktadır.

Bir teknoloji karşıtlığı propagandası yapmak yerine işe yarar teknolojileri sonuna kadar kullanmayı savunan Newport, 30 gün boyunca teknolojiden uzak bir yaşam sürmeyi ve 30 gün sonra geri dönüldügüunde zorunlu olmayan teknolojik ürünleri hayata geri almamayı tavsiye etmektedir. Teknolojik ürünlerin amaçlarını sorgulamamı gerektiği ve işe yaramayan aksine zaman çalan ürünlerin hayatımızdan tamamen çıkarılması gerektiğine kitapta sıklıkla bahsedilmektedir. Okurlarına teknoloji yoksunluğu ve yalnızlık yoksunluğunu aynı anda sunan Dijital Minimalizm kitabı iki yoksunluğun da ruhsal sağlığa ve hayat kalitesine olumsuz etkileri olduğunu örnekleriyle açıklamaktadır.

Kullanıcıları teknolojik ürün ve hizmetlerin faydalarını sorgulamaya davet eden Cal Newport okuyucularını fayda sağlamayan ve bir bağımlılığa dönüşen hareketlerden uzak durmaya davet etmektedir. Eve alınan teknolojik cihazlardan telefonlara indirilen gereksiz uygulamalara kadar birçok öğeyi yazılımsal ve donanımsal açıdan incelememiz gerektiğini ifade eden yazar teknolojinin kazandırdıklarının yanında kaybettirdiklerine de odaklanılması gerektiğini ve kaybedilen zamanın ya da dikkatin de değerli olduğunu hatırlatmaktadır ve zaman-dikkat kavramlarını sıklıkla kullanmaktadır.

Cal Newport'un kaleme aldığı Dijital Minimalizm kitabında belki de en vurucu kısım olarak "Dünyanın öbür ucundaki arkadaşlarıyla irtibatta kalmak için Facebook’a üye olmuşlardı fakat nihayetinde masanın öbür ucundaki arkadaşıyla bölünmeden, dolu dolu sohbet edemeyecek halde buldular kendilerini" sözü ön plana çıkmaktadır. Sosyal medya sosyalleştirir mi sorusuna net bir şekilde "hayır" diyen Newport, Dijital Minimalizm teknolojinin faydalarını hayatında hissetmek ama hayat da teknoloji tröstlerinin boyundurluğunda yaşamak istemeyen kişilerin okuması tavsiye edilen bir kitap. 


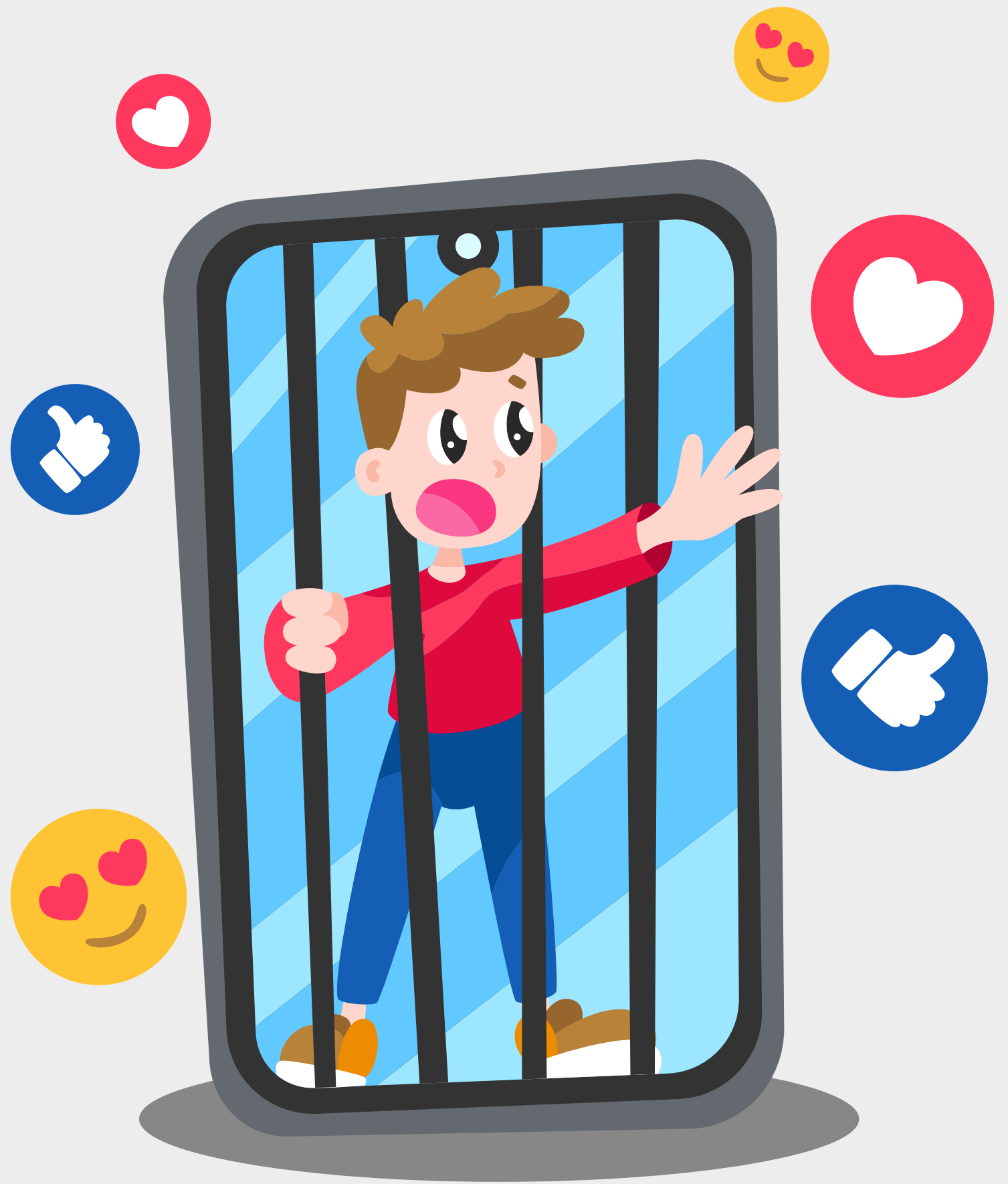

